\title{
Associations between musculoskeletal pain and work-related factors among public service sector computer workers in Kaunas County, Lithuania
}

Gintare Kaliniene*, Ruta Ustinaviciene, Lina Skemiene, Vidmantas Vaiciulis and Paulius Vasilavicius

\begin{abstract}
Background: Information technologies in occupational activities have been developing very rapid. Epidemiological studies have shown that musculoskeletal disorders are widely prevalent among employees working with a computer. The aim of this study was to evaluate the prevalence of musculoskeletal pain in various anatomical areas and its associations with individual, ergonomic, and psychosocial factors among computer workers of the public sector in Kaunas County, Lithuania.

Methods: The investigation consisting of two parts - questionnaire study (Nordic Musculoskeletal Questionnaire and Copenhagen Psychosocial Questionnaire) and direct observation (evaluation of work ergonomics using the Rapid Upper Limb Assessment [RULA]) - was carried out in three randomly selected public sector companies of Kaunas County. The representative study sample comprised 513 public service office workers. The prevalence of musculoskeletal pain in five anatomical areas of the body (shoulders, elbows, wrists/hands, as well as upper and low back) was evaluated.
\end{abstract}

Results: The prevalence rates of shoulder, elbow, wrist/hand, upper and low back pain were $50.5 \%, 20.3 \%, 26.3 \%$, $44.8 \%$, and $56.1 \%$, respectively. Individual factors such as gender, age, computer work experience, and body mass index were found as significant for musculoskeletal pain in various musculoskeletal regions. The respondents reporting pain in shoulder, wrist/hand, upper back, and low back areas had a statistically significantly higher mean RULA score. The duration of working with a computer was found as a significant factor for shoulder pain. High quantitative demands were related to musculoskeletal pain in all investigated anatomical areas expect for the low back; weak social support was a significant predictor for complaints in upper and low back areas.

Conclusion: This study confirmed associations between musculoskeletal pain and work ergonomics; therefore, preventive measures at the workplace should be directed to the improvement in ergonomic work environment, education, and workload optimization.

Keywords: Musculoskeletal pain, Computer work, Ergonomics, RULA

\footnotetext{
* Correspondence: gintare.kaliniene@lsmuni.lt

Department of Environmental and Occupational Medicine, Public Health

Faculty, Lithuanian University of Health Sciences, Tilzes 18, Kaunas LT-47181,

Lithuania
} 


\section{Background}

Musculoskeletal (MS) disorders are the most common work-related health problem in Europe, affecting millions of workers [1]. It is also the largest group of occupational diseases accounting for about one-third and more of all registered occupational diseases in the United States, Scandinavian countries, and Japan [2].

Information technologies have become indispensable in the office environment, which has led to intensified computer use. Many epidemiological studies show that MS complaints are widely prevalent among employees working with a computer [3-10]. Scientific reports indicate that computer users mostly report complaints about pain the neck area [7-11]. Our recent survey on MS complaints in the neck and their associations with workrelated factors has shown a very high prevalence (65.7\%) of MS pain in this area during a 12-month period [12]. However, complaints about pain in other anatomical body regions (shoulders, upper extremities, back) are also prevalent among computer users. Significant associations of these complaints with both physical [10, 13-15] and psychosocial [16-19] work environment are noted in studies. Research confirms that the working environment is not the only factor that has an impact on the development of MS disorders - individual characteristics such as gender, age, and body mass index (BMI) are also significant $[6,20-22]$. Some studies have reported evidence that MS disorders have a multifactorial origin [3, 23, 24]; however, other systematical reviews have not confirmed psychosocial factors to have a predictive value for MS complaints [25] or have not found even moderate evidence to confirm causative relationship between computer work and diagnosed MS disorders [26]. With the intention to fully consider the predisposing aspects of MS disorders, all factors - individual, physical, and psychosocial - were analyzed in this study.

The aim of this study was to evaluate the prevalence of MS pain in various anatomical areas and its associations with individual, ergonomic, and psychosocial factors among computer workers in the public sector of Kaunas County, Lithuania.

\section{Methods}

This study was part of the cross-sectional epidemiologic study "Ergonomics of computer work and its interface with work environment", carried out at the Department of Environmental and Occupational Medicine, Lithuanian University of Health Science, in 2010.

Scientific literature reports that frequency of the event of interest - MS disorders - in computer working populations varies from $6.6 \%$ to $70 \%$. The sample size calculation was based on the frequency with $5 \%$ probability of error and $95 \%$ reliability, and 0.5 relative frequency
[27], and this resulted in 384 participants needed to complete the study. Three institutions from the list of 12 public service institutions in Kaunas County were randomly selected to recruit participants. Employees whose work ware directly related to computer use were invited to participate in the study. A total of 570 questionnaires were distributed among employees, and 513 employees agreed to participate in the study and completed the questionnaire properly (response rate, $89.1 \%$ ).

The study protocol was approved by Kaunas Regional Ethics Committee for Biomedical Research, Lithuania (Protocol No. BE-2-13). The participation in the study was anonymous and voluntary; written informed consent to participate in the study was obtained from each participant together with the completed questionnaire.

\section{Questionnaires}

A three-part questionnaire was used in this study. The first part of the questionnaire included the questions that were designed to gather individual data of the respondents (age, gender, height, weight, and computer work experience). The division into age categories was done for the purpose of more convenient statistical analysis; the participants were divided into four age groups. Computer work experience was categorized into three groups. The second part was intended to assess the 12month prevalence of MS pain involving five anatomical areas of the body: shoulders, elbows, wrists/hands, as well as upper and low back. For this purpose, the Nordic Musculoskeletal Questionnaire was used [28]. The standardized Copenhagen Psychosocial Questionnaire was employed in order to evaluate the psychosocial work environment [29]. Five scales (quantitative demands, cognitive demands, responsibility demands, degree of freedom at work, and social support) of the Copenhagen Psychosocial Questionnaire, each made up of a certain combination of questions, were used in the study. Each question had five possible response options (always, often, sometimes, rarely, never or correct, almost correct, somewhat correct, almost wrong, wrong). Answers were transformed into a number between 0 and 100. An overall scale score was computed as the mean score across questions in each scale. Depending on the mean scale scores, the respondents were divided into three groups based on the margins of tertiles: high, average, and low levels of observed phenomena (Fig. 1). The internal reliability of all five scales and the Nordic Musculoskeletal Questionnaire scale was good (Cronbach's $\alpha>0.7$ ).

\section{Instrument of ergonomic investigation}

During this study, the Rapid Upper Limb Assessment (RULA) [30] was used in order to evaluate the work posture and performed movements among computer workers. If the investigator was not able to determine it 

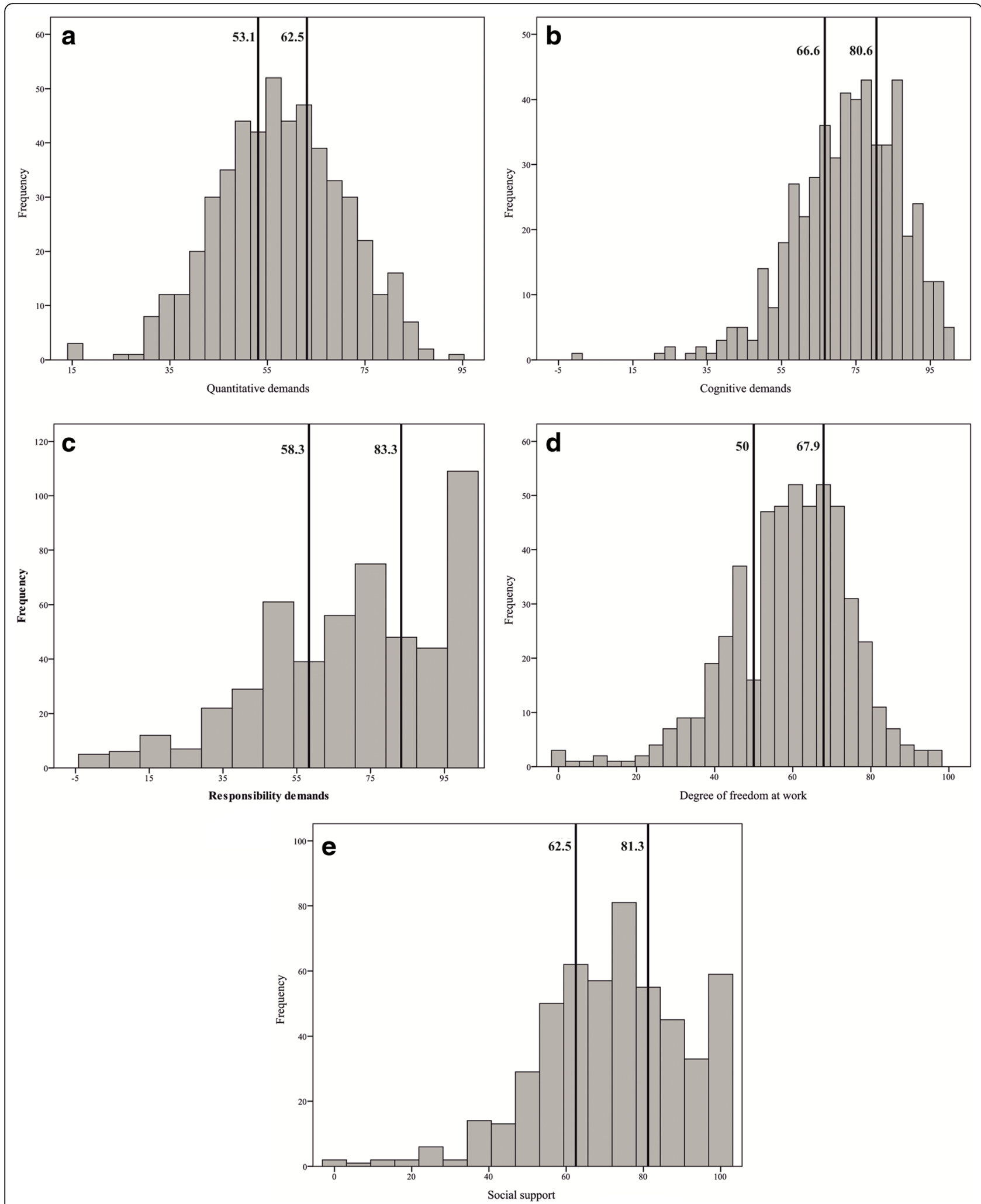

Fig. 1 Tertile margins of psychosocial characteristics: a Quantitative demands, b Cognitive demands, c Responsibility demands, d Degree of freedom at work, e Social support 
Table 1 Individual and work-related characteristics of the study population

\begin{tabular}{|c|c|}
\hline Factors & $N(\%)$ \\
\hline \multicolumn{2}{|l|}{ Individual } \\
\hline \multicolumn{2}{|l|}{ Gender } \\
\hline Men & $27(5.3)$ \\
\hline Women & $486(94.7)$ \\
\hline \multicolumn{2}{|l|}{ Age } \\
\hline 23-29 years & $55(10.7)$ \\
\hline 30-39 years & $91(17.7)$ \\
\hline $40-49$ years & $149(29.1)$ \\
\hline $50-70$ years & $218(42.5)$ \\
\hline \multicolumn{2}{|c|}{ Computer work experience } \\
\hline $1-5$ years & $115(22.4)$ \\
\hline $6-15$ years & $287(55.9)$ \\
\hline $16-36$ years & $111(21.7)$ \\
\hline \multicolumn{2}{|l|}{ BMl } \\
\hline$<18.5 \mathrm{~kg} / \mathrm{m}^{2}$ & $19(3.7)$ \\
\hline $18.6-24.9 \mathrm{~kg} / \mathrm{m}^{2}$ & $255(49.7)$ \\
\hline$>25 \mathrm{~kg} / \mathrm{m}^{2}$ & 239 (46.6) \\
\hline \multicolumn{2}{|l|}{ Work-related } \\
\hline \multicolumn{2}{|c|}{ Duration of working with a computer } \\
\hline$<4$ h/day & $20(3.9)$ \\
\hline 4-6 h/day & $88(17.2)$ \\
\hline$>6$ h/day & $405(78.9)$ \\
\hline \multicolumn{2}{|c|}{ Taking a break every $2 \mathrm{~h}$} \\
\hline Yes & $69(13.5)$ \\
\hline No & $444(86.5)$ \\
\hline \multicolumn{2}{|c|}{ Quantitative demands } \\
\hline Low & $208(40.5)$ \\
\hline Average & $143(27.9)$ \\
\hline High & $162(31.6)$ \\
\hline \multicolumn{2}{|l|}{ Cognitive demands } \\
\hline Low & $141(27.5)$ \\
\hline Average & $191(37.2)$ \\
\hline High & $181(35.3)$ \\
\hline \multicolumn{2}{|c|}{ Responsibility demands } \\
\hline Low & $142(27.7)$ \\
\hline Average & $170(33.1)$ \\
\hline High & $201(39.2)$ \\
\hline \multicolumn{2}{|c|}{ Degree of freedom at work } \\
\hline Low & $242(47.2)$ \\
\hline Average & $157(30.6)$ \\
\hline High & $114(22.2)$ \\
\hline
\end{tabular}

Table 1 Individual and work-related characteristics of the study population (Continued)

\begin{tabular}{ll} 
Social support & \\
Weak & $138(26.9)$ \\
Average & $183(35.7)$ \\
Strong & $192(37.4)$ \\
\hline
\end{tabular}

during surveillance, the employee was asked a few questions, e.g., how much time a day an employee spends talking on the phone pinching it to the ear with the help of the shoulder, while performing the routine tasks with the computer; how long he/she daily spends arranging the documents or talking to clients etc. without using a computer. Following this method, the work posture and movements of individual areas of the body were evaluated in scores with a higher score indicating greater stress for the MS area under investigation.

\section{Statistical analysis}

Statistical data analysis was performed using the SPSS (version 20.0) software package. Hypotheses about the equality between the averages of two quantitative variables and two percentage variables were examined by $U$ (non-parametric Mann-Whitney test) and $\mathrm{z}$ tests, respectively. Values of $P<0.05$ were considered statistically significant. In order to determine whether the selected individual and work-related factors were associated with MS complaints, binary logistic regression analysis (multivariate) was applied. The results of the analysis are presented as odds ratios (ORs) and $95 \%$ confidence intervals (CIs). The goodness-of-fit of the binary logistic regression models was evaluated using the HosmerLemeshow test.

\section{Results}

The overwhelming majority of the study population was women $(94.7 \%)$ with a mean age of $45.9 \pm 11.1$ years and mean computer work experience of $10.7 \pm 5.5$ years (Table 1). The majority of the respondents estimated they worked with a computer more than $6 \mathrm{~h}$ per day and did not have a brake every 2 working hours. The distribution analysis showed that about quarter of employees reported weak social support, one-third, high job demands and nearly half, low degree of freedom at work (Table 1). More than half of the employees complained about shoulder and low back pain, while elbow pain was least prevalent with one-fifth of the respondents complaining about it (Fig. 2).

The prevalence of MS symptoms was analyzed taking into account individual and work-related factors (Table 2). The youngest respondents significantly less frequently complained about pain in the shoulder than their older counterparts. Elbow pain was documented 


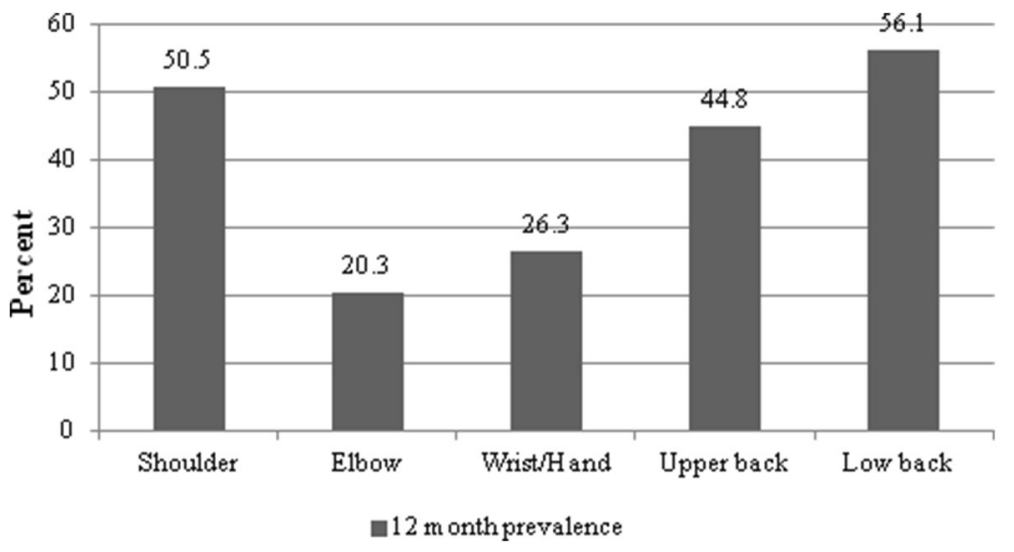

Fig. 2 Prevalence of musculoskeletal pain by different anatomical regions

more frequently among employees working with a computer for more than 5 years. A BMI greater than $25 \mathrm{~kg} /$ $\mathrm{m}^{2}$ had significant associations only with low back pain. Duration of working with a computer was significantly associated only with the prevalence of MS pain in the shoulder: the employees working with a computer more than $4 \mathrm{~h}$ per day more frequently complained about pain in this area. Wrist/hand and low back complains were more common among those who did not have any break every $2 \mathrm{~h}$. The respondents who reported low quantitative demands had pain less frequently in all investigated anatomical areas except for the low back. Low cognitive and responsibility demands were associated with less frequent pain in the shoulder, elbow, and upper back areas. Significantly higher frequencies of complaints in the shoulder and wrist/hand areas were observed for respondents reporting a low degree of freedom at work. Respondents with weak social support had a higher frequency of MS complaints in the low back area (Table 2).

The RULA score significantly differed comparing the groups of respondents with and without MS pain (Fig. 3). The respondents experiencing pain in shoulder, wrist/ hand, upper back, and low back areas had a statistically significantly higher mean RULA score.

Table 3 shows the results of logistic regression analysis investigating associations between individual and workrelated factors, and pain in different anatomical areas. The results of Hosmer-Lemeshow test revealed good fits for all models $\left(\chi^{2}=7.70, d f=8, P=0.46\right.$ for shoulder model; $\chi^{2}=10.02, d f=8, P=0.26$ for elbow model; $X^{2}=$ 4.61, $d f=8, P=0.79$ for wrists/hand model; $\chi^{2}=3.16$, $d f$ $=8, P=0.92$ for upper back model; $\chi^{2}=5.78, d f=8, P=$ 0.67 for low back model).

Women and 50-70-year olds were 6 and 2 times more likely than men and older respondents, respectively, to experience MS pain in the shoulder. Moreover, time spent working with a computer $4-6 \mathrm{~h}$ a day, higher levels of quantitative demands, and high level of responsibility demands were associated with an increased risk of having shoulder pain. For each one-point increase in the RULA score, the likelihood of having shoulder pain increased by $68 \%$.

Being a 50-70-year old and high levels of quantitative and responsibility demands were associated with a greater risk of experiencing elbow pain.

The likelihood of having wrist/hand pain was positively associated with a high level of quantitative demands. For each one-point increase in the RULA score, the likelihood of having wrist/hand pain increased by $59 \%$.

Computer work experience of 6-15 years, higher levels of quantitative and responsibility demands, and weak social support at work were found to be associated with a greater odds of experiencing upper back pain. For each one-point increase in the RULA score, the likelihood of having upper back pain increased by $38 \%$.

Having a BMI of $>25 \mathrm{~kg} / \mathrm{m}^{2}$, no taking a break every $2 \mathrm{~h}$, and weak social support at work were associated with an increased risk of having low back pain. For each one-point increase in the RULA score, the likelihood of having low back pain increased by $30 \%$.

\section{Discussion}

The aim of this cross-sectional study was to evaluate the prevalence of MS pain in various anatomical areas among computer workers in the public sector of Kaunas County. This study showed a high prevalence of MS pain in body parts such as shoulders, upper back, and low back among office workers. According to numerous studies, neck pain is in the leading position with the prevalence ranging from $19 \%$ to $70 \%$ in the population of office workers $[4,5,8,11,12,21,31-36]$. The prevalence of shoulder pain in this study was also high (50\%), and this is in line with the finding of Australian [4] and Chinese [31] studies, while Finnish [5] and German [37] 
Table 2 Prevalence of musculoskeletal pain with respect to individual and work-related factors

\begin{tabular}{|c|c|c|c|c|c|}
\hline Factors & $\begin{array}{l}\text { Shoulder } \\
N(\%)\end{array}$ & $\begin{array}{l}\text { Elbow } \\
\text { N (\%) }\end{array}$ & $\begin{array}{l}\text { Wrist/hand } \\
\text { N (\%) }\end{array}$ & $\begin{array}{l}\text { Upper back } \\
N(\%)\end{array}$ & $\begin{array}{l}\text { Low back } \\
N(\%)\end{array}$ \\
\hline \multicolumn{6}{|l|}{ Individual } \\
\hline \multicolumn{6}{|l|}{ Gender } \\
\hline Men & $4(14.8)$ & $2(7.4)$ & $4(14.8)$ & $9(45.5)$ & $15(55.6)$ \\
\hline Women & $255(52.5)^{*}$ & $102(21.0)$ & $131(27.0)$ & $221(33.3)$ & $273(56.2)$ \\
\hline \multicolumn{6}{|l|}{ Age } \\
\hline 23-29 years & $19(34.5)$ & $5(7.3)$ & $12(21.8)$ & $19(34.5)$ & $30(54.5)$ \\
\hline 30-39 years & $42(46.2)^{*}$ & $10(11.0)$ & $21(23.1)$ & $38(41.8)$ & $48(52.7)$ \\
\hline 40-49 years & $75(50.3)^{*}$ & $36(24.2)^{*}$ & $46(28.9)$ & $84(56.4)^{*}$ & $86(57.7)$ \\
\hline $50-70$ years & $123(56.4)^{*}$ & $54(24.8)^{*}$ & $59(27.1)$ & $89(40.8)$ & $124(56.1)$ \\
\hline \multicolumn{6}{|c|}{ Computer work experience } \\
\hline $1-5$ years & $48(41.7)$ & $14(1.2)$ & $26(22.6)$ & $40(34.8)$ & $62(53.9)$ \\
\hline $6-15$ years & $152(53.0)$ & $65(22.6)^{*}$ & $80(27.9)$ & $144(50.2)^{*}$ & $165(57.5)$ \\
\hline $16-36$ years & $59(53.2)$ & $25(22.5)^{*}$ & $29(26.1)$ & $46(41.4)$ & $61(55.0)$ \\
\hline \multicolumn{6}{|l|}{ BMI } \\
\hline$<18.5 \mathrm{~kg} / \mathrm{m}^{2}$ & $9(47.4)$ & $0(0)$ & $4(21.1)$ & $6(31.6)$ & $8(42.1)$ \\
\hline $18.6-24.9 \mathrm{~kg} / \mathrm{m}^{2}$ & $128(50.2)$ & 50 (19.6) & $71(27.8)$ & $122(47.8)$ & $133(51.0)$ \\
\hline$>25 \mathrm{~kg} / \mathrm{m}^{2}$ & $122(51.0)$ & $54(22.6)$ & $60(25.1)$ & $102(41.7)$ & $144(60.3)^{*}$ \\
\hline \multicolumn{6}{|l|}{ Work-related } \\
\hline \multicolumn{6}{|c|}{ Duration of working with a computer } \\
\hline$<4$ h/day & $6(30)$ & $6(30.0)$ & $5(25.0)$ & $8(40)$ & $8(40.0)$ \\
\hline 4-6 h/day & $47(53.4)^{*}$ & $14(15.9)$ & $17(19.3)$ & $36(40.9)$ & $55(62.5)$ \\
\hline$>6 \mathrm{~h} /$ day & $206(50.9)^{*}$ & $84(20.7)$ & $113(27.9)$ & $186(45.9)$ & $225(55.6)$ \\
\hline \multicolumn{6}{|c|}{ Taking a break every $2 \mathrm{~h}$} \\
\hline Yes & $30(43.5)$ & $15(21.7)$ & $13(18.8)$ & $26(37.7)$ & $31(44.9)$ \\
\hline No & $229(51.6)$ & $89(20.0)$ & $122(27.5)^{*}$ & $204(45.9)$ & $257(57.9)^{*}$ \\
\hline \multicolumn{6}{|c|}{ Quantitative demands } \\
\hline Low & $84(40.4)$ & $32(15.4)$ & $42(20.2)$ & $73(35.1)$ & $112(53.8)$ \\
\hline Average & $80(55.9)^{*}$ & $30(21.0)$ & $37(25.9)$ & $69(48.3)^{*}$ & $79(55.2)$ \\
\hline High & $95(58.6)^{*}$ & $42(25.9)^{*}$ & $56(34.6)^{*}$ & $88(54.3)^{*}$ & $97(59.9)$ \\
\hline
\end{tabular}


Table 2 Prevalence of musculoskeletal pain with respect to individual and work-related factors (Continued)

\begin{tabular}{|c|c|c|c|c|c|}
\hline \multicolumn{6}{|c|}{ Cognitive demands } \\
\hline Low & $59(41.8)$ & $17(12.1)$ & $31(22.0)$ & $56(39.7)$ & $74(52.5)$ \\
\hline Average & $96(50.3)$ & $41(21.5)^{*}$ & $54(28.3)$ & 78 (40.8) & 114 (59.7) \\
\hline High & $104(50.5)^{*}$ & $46(25.4)^{*}$ & $50(27.6)$ & $96(53.0)^{*}$ & $100(55.2)$ \\
\hline \multicolumn{6}{|c|}{ Responsibility demands } \\
\hline Low & $63(44.4)$ & $23(16.2)$ & 35 (24.6) & $51(35.9)$ & $80(56.3)$ \\
\hline Average & 79 (46.5) & $28(16.5)$ & $45(26.5)$ & $81(47.6)^{*}$ & $98(57.6)$ \\
\hline High & $117(58.2)^{*}$ & $53(26.4)^{*}$ & $55(27.4)$ & $98(48.8)^{*}$ & $110(54.7)$ \\
\hline \multicolumn{6}{|c|}{ Degree of freedom at work } \\
\hline Low & $135(55.8)^{*}$ & $52(21.5)$ & $72(29.8)^{*}$ & $114(47.1)$ & $138(57.0)$ \\
\hline Average & $73(46.5)$ & $33(21.0)$ & $40(25.5)$ & $69(43.9)$ & $87(55.4)$ \\
\hline High & $51(44.7)$ & $19(16.7)$ & $23(20.2)$ & $47(41.2)$ & $63(55.3)$ \\
\hline \multicolumn{6}{|c|}{ Social support } \\
\hline Weak & $75(54.3)$ & $31(22.5)$ & $37(26.8)$ & $73(52.9)^{*}$ & $89(64.5)^{*}$ \\
\hline Average & $85(46.4)$ & 34 (18.6) & $46(25.1)$ & $77(42.1)$ & $101(55.2)$ \\
\hline Strong & 99 (51.6) & $39(20.3)$ & $52(27.1)$ & $80(41.7)$ & $98(51.0)$ \\
\hline
\end{tabular}

$\mathrm{z}$ test, ${ }^{*} P<0.05$ - comparing with: youngest age group; smallest work experience group; $18.6-24.9 \mathrm{~kg} / \mathrm{m}^{2} \mathrm{BMl}$ group; $<4 \mathrm{~h} /$ day working with computer respondents group; those who taking break every two hours; working in a positive work environment with respect to current psychosocial factor 


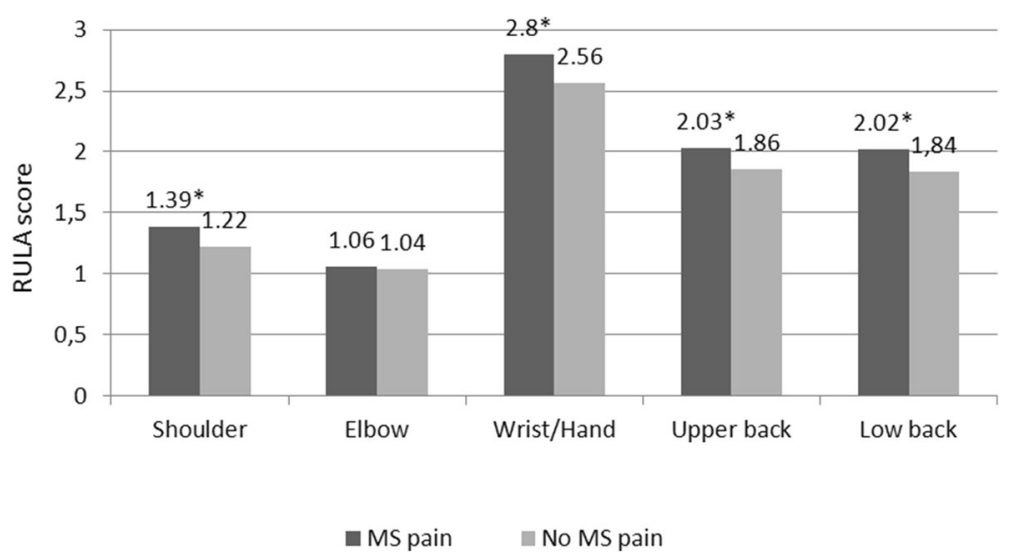

Fig. 3 Mean RULA posture and movement scores in the groups of respondents with and without musculoskeletal (MS) pain

studies documented a lower prevalence of MS complaints in this area. It is worth noting that some epidemiological studies report the prevalence of neck and shoulder complaints or complaints in the arm, neck, and shoulder areas together because of similar etiology factors. In different studies, the prevalence of pain in these localizations was also about $50 \%$ [10, 33, 38]. Pain in arm, wrist, and hand areas is also common, and typically about $30 \%$ of computer workers have MS complaints in these anatomical regions $[4,31,33]$. In our study, about quarter of the respondents complained about pain in elbow and hand/wrist regions (20.6\% and $26.3 \%$, respectively). Back pain is a very common MS complaint in the general population as well, and according to a systematic review by Walker, which included 53 studies, it ranges between $22 \%$ and $65 \%$ [39], showing that there are a lot of predisposing risk factors associated not only with the work environment, but also with domestic or other activities [20]. Our research also showed a high prevalence rate of back pain accounting for $44.8 \%$ in the upper back and $56.1 \%$ in the low back.

Since computerization levels in the office work environment have dramatically increased, the question of a multifactorial origin of MS disorders is being discussed by scientists. There is evidence that all predisposing factors - individual, ergonomic, and psychosocial - are related to the development of MS complaints [3, 23, 24]. The results of our study also confirmed that MS pain was associated with individual and ergonomic as well as psychosocial factors among computer workers.

Contrary to previous studies that confirmed differences between genders and documented that women are more likely to experience MS pain [4-6, 8, 20-22, 40], our study showed that only shoulder pain was more frequent among women and this was confirmed by the results of multivariate logistic regression as well. However, it should be mentioned that women comprise a major proportion of Lithuanian public office workers, and in our study, men accounted only for $5.3 \%$ of the overall study population. Because of this limitation, the distribution of MS pain in the male group could not reflect a real situation.

In our study, the frequency of complaints in almost all anatomical regions was higher in older and oldest respondents' age groups as compared with the youngest group. Moreover, multivariate logistic regression analysis showed that the oldest participants (50-70 years old) were more than 2 and 3 times as likely to have MS complaints in shoulder and elbow areas. Some epidemiological studies have reported that middle-aged employees are most vulnerable to pain in neck and shoulder localizations [4, 8, 41-43]. One could assume that the respondents of this particular age group have the largest experience of working with computers; however, our study did not confirm that biggest work experience associated with higher prevalence of MS pain.

Among individual risk factors, also BMI and its relationship with MS pain were investigated. A BMI of $>25 \mathrm{~kg} / \mathrm{m}^{2}$ was found to be associated with MS pain in the low back anatomical region, and this is in agreement with other epidemiological studies [20, 44].

During comprehensive assessment of the risk of complaints about MS pain, it is important to take into account ergonomics at the workplace for those who work with a computer. Objective investigations on muscular activity have documented increased muscle tension during computer work [40, 45-47]. Other epidemiological studies have shown that improper localization of equipment in the computerized workplace is associated with MS pain $[48,49]$.

Due to the fact that not only inadequacy of the workstation can determine the worker's posture and movements, we assessed the ergonomics of computer work by the RULA method, which evaluates harmful posture and movements for certain areas of the body. The main strength of this study was ergonomic evaluation with the 
Table 3 Logistic regression model for musculoskeletal pain in various anatomical regions (fully adjusted)

\begin{tabular}{|c|c|c|c|c|c|c|c|c|c|c|}
\hline \multirow[t]{3}{*}{ Factor } & \multicolumn{10}{|c|}{ Musculoskeletal region } \\
\hline & \multicolumn{2}{|c|}{ Shoulder } & \multicolumn{2}{|c|}{ Elbow } & \multicolumn{2}{|c|}{ Wrist/hand } & \multicolumn{2}{|c|}{ Upper back } & \multicolumn{2}{|c|}{ Low back } \\
\hline & OR & $95 \% \mathrm{Cl}$ & OR & $95 \% \mathrm{Cl}$ & OR & $95 \% \mathrm{Cl}$ & OR & $95 \% \mathrm{Cl}$ & OR & $95 \% \mathrm{Cl}$ \\
\hline \multicolumn{11}{|l|}{ Gender } \\
\hline Men & 1 & & 1 & & 1 & & 1 & & 1 & \\
\hline Women & 6.1 & $1.95-19.08$ & 2.95 & $0.59-14.58$ & 1.52 & $0.491-4.88$ & 1.21 & $0.50-2.93$ & 1.12 & $0.48-2.61$ \\
\hline \multicolumn{11}{|l|}{ Age } \\
\hline 23-29 years & 1 & & 1 & & 1 & & 1 & & 1 & \\
\hline 30-39 years & 1.48 & $0.65-3.37$ & 1.15 & $0.30-4.34$ & 0.78 & $0.30-2.05$ & 0.80 & $0.34-1.86$ & 0.92 & $0.41-2.06$ \\
\hline $40-49$ years & 1.89 & $0.65-3.53$ & 2.94 & $0.62-8.21$ & 1.09 & $0.41-2.91$ & 1.62 & $0.68-3.85$ & 1.07 & $0.46-2.46$ \\
\hline $50-70$ years & 2.16 & $1.02-4.99$ & 3.38 & $1.87-12.05$ & 1.11 & $0.41-2.00$ & 0.93 & $0.39-2.23$ & 0.91 & $0.42-2.23$ \\
\hline \multicolumn{11}{|c|}{ Computer work experience } \\
\hline $1-5$ years & 1 & & 1 & & 1 & & 1 & & 1 & \\
\hline $6-15$ years & 1.03 & $0.56-1.86$ & 1.49 & $0.66-3.37$ & 1.31 & $0.65-2.62$ & 1.87 & $1.01-3.46$ & 0.90 & $0.50-1.63$ \\
\hline $16-36$ years & 1.04 & $0.51-2.09$ & 1.46 & $0.58-3.62$ & 1.16 & $0.52-2.60$ & 1.42 & $0.70-2.91$ & 0.81 & $0.41-1.61$ \\
\hline \multicolumn{11}{|l|}{ BMI } \\
\hline$<18.5 \mathrm{~kg} / \mathrm{m}^{2}$ & 0.79 & $0.50-1.25$ & 0.88 & $0.53-1.46$ & 0.77 & $0.22-2.61$ & 0.75 & $0.24-2.31$ & 1.48 & $0.55-3.99$ \\
\hline $18.6-24.9 \mathrm{~kg} / \mathrm{m}^{2}$ & 1 & & 1 & & 1 & & 1 & 1 & 1 & \\
\hline$>25 \mathrm{~kg} / \mathrm{m}^{2}$ & 1.44 & $0.75-2.77$ & 1.02 & $0.64-2.45$ & 0.17 & $0.45-1.15$ & 0.70 & $0.46-1.08$ & 1.50 & $1.24-4.28$ \\
\hline
\end{tabular}

Duration of working with a computer

$\begin{array}{lllllllllll}<4 \text { h/day } & 1 & & 1 & & & & 1 & & 1 \\ \text { 4-6 h/day } & \mathbf{3 . 0 3} & \mathbf{1 . 9 7 - 9 . 4 0} & 0.41 & 0.14-1.70 & 0.46 & 0.17-1.90 & 0.70 & 0.23-2.13 & 2.14 & 0.76-6.01 \\ >6 \text { h/day } & 2.40 & 0.81-7.11 & 0.59 & 0.22-2.13 & 0.70 & 0.22-2.22 & 0.93 & 0.32-2.73 & 1.58 & 0.59-4.21\end{array}$

Taking a break every $2 \mathrm{~h}$

Yes

No

RULA score

1.68

0.44-1.46

1

0.61

0.29-1.27

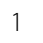

1.31

0.63-2.68

0.69-3.81
1.15-2.21

\section{1}

0.95

1.38
(2)

0.51-1.76

1.04-1.75

\section{1}

1.30

1.16-2.95

Quantitative demands

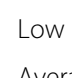

Average

1

High

1.67

1.05-2.68

\section{1}

1.27

0.70-2.95

1.75

1.12-3.11

Cognitive demands

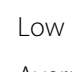

Average

\section{1}

High

1.17

0.73-1.89

\section{1}

Responsibility demands

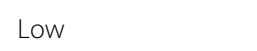

Average

1.18

0.72-1.93

1.14-3.14

1.89

$0.71-2.04$

1.52

0.78-2.95

1.51

$0.76-3.00$

High

Degree of freedom at work

\begin{tabular}{|c|c|c|c|c|c|c|c|c|c|c|}
\hline Low & 0.94 & $0.55-1.59$ & 1.61 & $0.78-2.82$ & 1.25 & $0.66-2.34$ & 1.26 & $0.71-2.23$ & 1.05 & $0.64-1.71$ \\
\hline Average & 1.39 & $0.84-1.59$ & 1.48 & $0.81-3.19$ & 1.44 & $0.81-2.56$ & 1.34 & $0.73-2.21$ & 1.05 & $0.62-1.76$ \\
\hline High & 1 & & 1 & & 1 & & 1 & & 1 & \\
\hline
\end{tabular}


Table 3 Logistic regression model for musculoskeletal pain in various anatomical regions (fully adjusted) (Continued)

\begin{tabular}{|c|c|c|c|c|c|c|c|c|c|c|}
\hline \multicolumn{11}{|c|}{ Social support } \\
\hline Weak & 1.35 & $0.82-2.16$ & 1.31 & $0.62-1.93$ & 0.88 & $0.53-1.46$ & 1.74 & $1.07-2.83$ & 1.86 & $1.15-3.00$ \\
\hline Average & 0.97 & $0.61-1.52$ & 1.10 & $0.73-2.35$ & 0.66 & $0.56-1.63$ & 1.10 & $0.70-1.75$ & 1.22 & $0.79-1.90$ \\
\hline Strong & 1 & & 1 & & 1 & & 1 & & 1 & \\
\hline
\end{tabular}

RULA method applied by the investigators in order to achieve greater objectivity. The results showed that a higher RULA score was statistically significantly associated with a greater risk of having MS complaints in the shoulder, wrist/hand, upper back, and low back anatomical areas.

In many epidemiological studies, MS pain in shoulder area was investigated together with neck complaints; therefore, work posture and movements were identified as significant factors having an impact on pain in both neck and shoulder areas $[13,14]$. In our study, the duration of work with a computer for 4-6 h a day increased the likelihood of experiencing pain in the shoulder area, but Blatter et al. showed that employees who work with a computer more than $6 \mathrm{~h}$ per day were at increased risk of shoulder pain [50]. Awkward posture and movements of computer workers have been confirmed as significant risk factors for MS pain in the arm area [10, 15, 32, 51, 52]; however, our data showed significant associations these factors and pain only in hand/wrist anatomical area.

The neck and shoulders are the most affected anatomical regions of the human body in computer workers, and for this reason, MS pain in the back including both upper and low back is less investigated in scientific studies involving computer workers as a study population. Despite this, some epidemiological studies [4, 32, 49] as well as our data confirmed associations between MS pain in the back area and inadequate work posture and movements.

Development of information technologies and computerization has led to many changes in office workers' professional practice and constantly increasing job demands. Negative consequences of computerization due to increasing workload, employer expectations, or job tension to employees were recognized [53], and high job demands were found to be associated with MS symptoms in many populations of office workers [16, 10, 54]. Our study also demonstrated that quantitative job demands were significantly associated with MS complaints in almost all investigated anatomical areas except for the low back. Responsibility demands were found to be a significant factor for shoulder, elbow, and upper back complaints, while weak social support had a significant impact on both upper and low back pain. The observation that the odds ratios of all MS pain-predisposing factors - individual, psychosocial, and ergonomic - were almost of equal magnitude suggest that their contribution to etiology of MS pain is very similar.

\section{Conclusions}

The prevalence of MS pain among computer users was high, with shoulders and low back being the most affected anatomical areas. Significant associations between individual factors, work ergonomics (inappropriate posture and movements), and MS pain were found. Workrelated psychosocial factors had a significant impact on experiencing pain as well: high quantitative demands were associated with MS complaints in almost all anatomical areas, and weak social support was a significant predictor for MS complaints in the upper and low back areas.

Preventive measures at the workplace should be directed to the improvement in ergonomic work environment and reducing job strain caused inadequate workload, high responsibilities, and weak social support.

\section{Abbreviations}

BMI: Body mass index; Cl: Confidence interval; MS: Musculoskeletal; OR: Odds ratio; RULA: Rapid upper limb assessment

\section{Acknowledgments \\ The authors wish to thank the leaders of Kaunas County public service companies for the partnerships. We express gratitude to our Department of Environmental and Occupational Medicine colleagues for provided critical input in all phases of this study.}

\section{Funding}

Any funding for this study was not obtained.

Availability of data and materials

All data concerning the resarche are presented in the manuscript.

\section{Authors' contributions}

GK and RU: substantial contribution to conception and design. GK and W: acquisition of data, and analysis an interpretation of data. LS, RU and PV: drafting the article or revising it critically for important intellectual content. All authors: final approval of the version to be published.

\section{Competing interests}

The authors have no competing interests to declare.

\section{Consent for publication}

Not applicable.

\section{Ethics approval and consent to participate}

The study protocol was approved by Kaunas Regional Biomedical Research Ethics Committee (Lithuania) (Protocol No. BE-2-13). Participation in the study was anonymous and voluntary. Informed agreement to participate in the study was provided with the completed questionnaire.

Received: 27 April 2016 Accepted: 1 October 2016

Published online: 07 October 2016 


\section{References}

1. Health and safety at work in Europe (1999-2007). European Commission, Employment, Social Affairs and Equal Opportunities, Luxembourg, 2010. http://ec.europa.eu/eurostat/documents/3217494/5718905/KS-31-09-290-EN PDF/88eef9f7-c229-40de-b1cd-43126bc4a946. Accessed 23 Feb 2016

2. Punnett $\mathrm{L}$, Wegman $\mathrm{DH}$. Work-related musculoskeletal disorders: the epidemiologic evidence and the debate. J Electromyogr Kinesiol. 2004;14:13-23.

3. Wahlstrom J. Ergonomics, musculoskeletal disorders and computer work. Occup Med. 2005;55:168-76.

4. Cook C, Limerick BR, Chang S. The prevalence of neck and upper extremity musculoskeletal symptoms in computer mouse users. Int J Ind Ergon. 2000:26:347-56

5. Sillanpää J, Huikko S, Nyberg M, Kivi P, Laippala P, Uitti P. Effect of work with visual display units on musculoskeletal disorders in the office environment. Occup Med (Lond). 2003;53:443-51

6. Jensen C. Development of neck and hand-wrist symptoms in relation to duration of computer use at work. Scand J Work Environ Health. 2003;29(3):197-205.

7. Jensen C, Finsen L, Sogaard K, Christensen H. Musculoskeletal symptoms and duration of computer and mouse use. Int J Ind Ergon. 2002;30(4-5):265-75.

8. Canie B, Danneels L, Tiggelen D, De Loose V, Cambier D. Individual and work related risk factors for neck pain among office workers: a cross sectional study. Eur Spine J. 2007;16:679-86.

9. Eltayeb S, Staal BJ, Kennes J, Lamberts P, Bie R. Prevalence of complains of arm, neck and shoulder among computer office workers and psychometric evaluation of a risk factor questionnaire. BMC Muscoskel Disord. 2007;8:68.

10. Ranasinghe P, Perera YS, Lamabadusuriya DA, Kulatunga S, Jayawardana N Rajapakse S, et al. Work related complaints of neck, shoulder and arm among computer office workers: a cross-sectional evaluation of prevalence and risk factors in a developing country. Environmental Health. 2011;10:70

11. Oha K, Animägi L, Pääsuke $M$, Coggon D, Merisalu E. Individual and workrelated risk factors for musculoskeletal pain: a cross-sectional study among Estonian computer users. BMC Muscoskel Disord. 2014;15:181.

12. Kaliniene G, Ustinaviciene R, Skemiene L, Januskevicius V. Associations between the neck musculoskeletal complaints and work related factors among public service computer workers in Kaunas. Int J Occup Med Environ Health. 2013:26(5):670-81.

13. Marcus M, Gerr F, Monteilh C, Ortiz DJ, Gentry E, Cohen S, et al. A prospective study of computer users: II. Postural risk factors for musculoskeletal symptoms and disorders. Am J Ind Med. 2002;41:236-49.

14. Eltayeb S, Staal JB, Hassan A, de Bie RA. Work Related Risk Factors for Neck Shoulder and Arms Complaints: A Cohort Study among Dutch Computer Office Workers. J Occup Rehabil. 2009;19:315-22.

15. Heuvel SG, Beek AJ, Blatter BM, Bongers PM. Physical risk factors for neck and upper limb disorders in industrial and office workers: results from the smash study. Occup Environ Med. 2004;61:e47.

16. Griffiths KL, Mackey MG, Adamson BJ. Behavioral and Psychophysiological Responses to Job Demands and Association with Musculoskeletal Symptoms in Computer Work. J Occup Rehabil. 2011;21:482-92.

17. Van den Heuvel SG, Van der Beek AJ, Blatter BM, et al. Psychosocial work characteristics in relation to neck and upper limb symptoms. Pain. 2005;114:47-53.

18. Torp SM, Rijse T, Moen BE. The impact of psychosocial work factors on musculoskeletal pain: a prospective study. J Occup Environ Med. 2001:43:120-6.

19. Zakerian SA, Subramaniam ID. The Relationship Between Psychosocial Work Factors, Work Stress and Computer-Related Musculoskeletal Discomforts Among Computer Users in Malaysia. Int J Occup Safety Ergono. 2009;15(4):425-34.

20. Spyropoulos P, Papathanasiou G, Georgoudis G, Chronopoulos E, Koutis H, Koumoutsou F. Prevalence of Low Back Pain in Greek Public Office Workers. Pain Physician. 2007;10:651-60.

21. Akrouf QAS, Crawford JO, Al-Shatti AS, Kamel I. Musculoskeletal disorder among bank office workers in Kuwait. Eastern Mediterranean Health Journal. 2010;16(1):94-100

22. Juul-Kristensen B, Søgaard K, Strøyer J, Jensen C. Computer users' risk factors for developing shoulder, elbow and back symptoms. Scand J Work Environ Health. 2004;30(5):390-8.

23. Griffiths KL, Martin G, Mackey M, Adamson BJ. The Impact of a Computerized Work Environment on Professional Occupational Groups and Behavioural and Physiological Risk Factors for Musculoskeletal Symptoms: A Literature Review. J Occup Rehabil. 2007;17:743-65.
24. Feveile $H$, Jensen $\mathrm{C}$, Burr $\mathrm{H}$. Risk factors for neck-shoulder and wrist-hand symptoms in a 5-year follow-up study of 3,990 employees in Denmark. Int Arch Occup Environ Health. 2002;75(4):243-51.

25. Paksaichol A, Janwantanakul P, Purepong N, Pensri P, van der Beek AJ. Office workers' risk factors for the development of non-specific neck pain: a systematic review of prospective cohort studies. Occup Environ Med. 2012;69(9):610-8

26. Waersted M, Hanvold TN, Veiersted KB. Computer work and musculoskeletal disorders of the neck and upper extremity: A systematic review. BMC Muscoskel Disord. 2010;11:79.

27. Riffenburgh, Robert H. Statistics in Medicine. Burlington: Academic; 2011

28. Kuorinka I, Jonsson B, Kilbom A, Vinterberg $H$, Biering-Sorensen $F$, Andersson G, et al. Standardised Nordic questionnaires for the analysis of musculoskeletal symptoms. Applied Ergonomics. 1987;18(3):233-7.

29. Kristensen TS. A new tool for assessing psychosocial factors at work: The Copenhagen Psychosocial Questionnaire. TUTB Newsl. 2002;19-20:45.

30. Lueder R. A Proposed RULA for Computer Users. San Francisco: UC Berkeley Center for Occupational \& Environmental Health Continuing Education Program; 1996.

31. Wu S, He L, Li J, Wang J, Wang S. Visual Display Terminal Use Increases the Prevalence and Risk of Work-related Musculoskeletal Disorders among Chinese Office Workers: A Cross-sectional Study. J Occup Health. 2012;54:34-43.

32. Jensen C, Borg V, Finsen L, Hansen K, Juul-Kristensen B, Christensen H. Job demands, muscle activity and musculoskeletal symptoms in relation to work with the computer mouse. Scand J Work Environ Health. 1998;24(5):418-24.

33. Rocha LE, Glina DMR, Marinho MF, Nagasato D. Risk Factors for Musculoskeletal Symptoms among Call Center Operators of a Bank in São Paulo. Brazil. Industrial Health. 2005;43:637-46.

34. Radulović B, Huršidić-Radulović A. Musculoskeletal and eye symptoms in computer users at work. Arh Hig RadaToksikol. 2012;63:215-8

35. Korpinen L, Pääkkönen R, Gobba F. White-collar workers' self-reported physical symptoms associated with using computers. Int J Occup Saf Ergon. 2012;18(2):137-47

36. Ye Z, Abe Y, Kusano Y, Takamura N, Eida K, Takemoto T, et al. The Influence of Visual Display Terminal Use on the Physical and Mental Conditions of Administrative Staff in Japan. J PhysiolAnthropol. 2007;26:69-73.

37. Klussmann A, Gebhardt H, Liebers F, Rieger MA. Musculoskeletal symptoms of the upper extremities and the neck: A cross-sectional study on prevalence and symptom predicting factors at visual display terminal (VDT) workstations. BMC Muscoskel Disord. 2008;9:96.

38. Bhanderi D, Choudhary SK, Parmar L, Doshi V. A Study of Occurrence of Musculoskeletal Discomfort Computer Operators. Indian J Community Med. 2008:33(1):65-6.

39. Walker BF. The Prevalence of Low Back Pain: A Systematic Review of the Literature from 1966 to 1998. J Spinal Disord. 2000;13(3):205-17.

40. Johnston V, Jull G, Darnell R, Jimmieson NL, Souvlis T. Alterations in cervical muscle activity in functional and stressful tasks in female office workers with neck pain. Eur J Appl Physiol. 2008:103(3):253-64.

41. El-Bestar SF, El-Mitwalli AA, Khashaba EO. Neck-upper extremity musculoskeletal disorders among workers in the telecommunications company at Mansoura. Int J Occup Saf Ergon. 2011;17(2):195-205.

42. Tornqvist EW, Hagberg M, Hagman M, Risberg EH, Toomingas A. The influence of working conditions and individual factors on the incidence of neck and upper limb symptoms among professional computer users. Int Arch Occup Environ Health. 2009;82:689-702

43. Gerr F, Marcus M, Ensor C, Kleinbaum D, Cohen S, Edwards A, et al. A prospective Study of Computer Users: Study Design and Incidence of Musculoskeletal Symptoms and Disorders. Am J Ind Med. 2002:41:221-35.

44. Liuke M, Solovieva S, Lamminen A, Luoma K, Leino-Arjas P, Luukkonen R, et al. Disc degeneration of the lumbar spine in relation to overweight. Int J Obes (Lond). 2005:29:903-8.

45. Szeto GPY, Straker LM, O'Sullivan PB. Neck shoulder muscle activity in general and task-specific resting postures of symptomatic computer users with chronic neck pain. Manual Therapy. 2009;14:338-45.

46. Birch L, Juul-Kristensenls B, Chri J, Finsen L, Christensen H. Acute response to precision, time pressure and mental demand during simulated computer work. Scand J Work Environ Health. 2000;26(4):299-305.

47. Johnston V, Jull G, Souvlis T, Jimmieson NL. Neck movement and muscle activity characteristics in female office workers with neck pain. Spine. 2008;33(5):555-63. 
48. Gerr F, Marcus M, Monteilh C. Epidemiology of musculoskeletal disorders among computer users: lesson learned from the role of posture and keyboard use. J Electromyogr Kinesiol. 2004;14:25-31.

49. Gerr F, Monteilh CP, Marcus M. Keyboard use and musculoskeletal outcomes among computer users. J Occup Rehabil. 2006;16:265-77.

50. Blatter BM, Bongers PM. Duration of computer use and mouse use in relation to musculoskeletal disorders of neck or upper limb. Int J Ind Ergon. 2002;30:295-306.

51. Andersen JH, Harhoff M, Grimstrup S, Vilstrup I, Lassen CF, Brandt LP, et al. Computer mouse use predicts acute pain but not prolonged or chronic pain in the neck and shoulder. Occup Environ Med. 2008;65:126-31.

52. Bergquist U. Health problems during work with visual display terminals. Sweden: Institute of Enviromental medicine, Department of Neuromedicine, National Institute of Occupational Health; 2003.

53. Bridger RS, Brasher K. Cognitive task demands, self-control demands and the mental well-being of office workers. Ergonomics. 2011;54(9):830-9.

54 Sharan D, Parijat P, Sasidharan AP, Ranganathan R, Mohandoss M, Jose J. Workstyle Risk Factors for Work Related Musculoskeletal Symptoms among Computer Professionals in India. J Occup Rehabil. 2011;21:520-5.

\section{Submit your next manuscript to BioMed Central} and we will help you at every step:

- We accept pre-submission inquiries

- Our selector tool helps you to find the most relevant journal

- We provide round the clock customer support

- Convenient online submission

- Thorough peer review

- Inclusion in PubMed and all major indexing services

- Maximum visibility for your research

Submit your manuscript at www.biomedcentral.com/submit 